\title{
Morphological and biochemical diversity of Spiraea hypericifolia (Rosaceae) growing under natural conditions in Novosibirsk Oblast
}

\author{
Vera A. Kostikova ${ }^{1}$, Sheng-Xiang $\mathrm{Yu}^{2}$, Mathew T. Sharples ${ }^{3}$ \\ ${ }^{1}$ Central Siberian Botanical Garden, SB RAS, 630090 Novosibirsk, Russia \\ ${ }^{2}$ Institute of Botany, Chinese Academy of Sciences, 100093 Beijing, China \\ ${ }^{3}$ University of Colorado, 80309 Boulder, Colorado, U.S.A.
}

\begin{abstract}
A study on some morphological characteristics and the set and levels of phenolic compounds was performed for the first time on Spiraea hypericifolia L. (Rosaceae Juss.) growing under natural conditions in the Novosibirsk region (four sites). Two phenotypic varieties of $S$. hypericifolia were identified. Twenty-three phenolic compounds were found in aqueous-ethanol extracts from $S$. hypericifolia leaves by highperformance liquid chromatography. Chlorogenic, $p$-hydroxybenzoic, and $p$-coumaric acids and quercetin, hyperoside, isoquercitrin, avicularin, rutin, and astragalin were identified among them. Hyperoside $(6.7-20.5 \mathrm{mg} / \mathrm{g})$ is the main phenolic compound in $S$. hypericifolia leaves. Flavonoid aglycones were prepared from the leaves by hydrochloric-acid hydrolysis of the aqueous-ethanol extracts (1:1). Three flavonol aglycones (quercetin, kaempferol, and isorhamnetin) were identified in the extract hydrolysates from $S$. hypericifolia leaves by chromatographic analysis. Quercetin glycosides proved to be predominant phenolic compounds in all the extract hydrolysates. A comparative analysis was performed on the levels of phenolic compounds in leaves among $S$. hypericifolia from the different sites and between the two varieties of $S$. hypericifolia. It was revealed that an increase in plant size by approximately twofold correlates with a decrease in concentrations of the identified flavonoids and phenolcarboxylic acids in S. hypericifolia leaves.
\end{abstract}

\section{Introduction}

Spiraea hypericifolia L. (Rosaceae Juss.) is a shrub 50-80 cm tall with oblong-elliptical smooth-edged leaves. White flowers, $5-8 \mathrm{~mm}$ in diameter, are combined into numerous few-flowered sessile umbrellas. This plant grows in the steppe zone and the steppe belt of mountains, namely, in steppes, in steppe meadows, and on rocky slopes. In Russia, it occurs in the European part of the country, in Crimea, and in Siberia. Outside of Russia, it occurs in Europe and Asia [1].

As far as we know, there are no comparative morphological and biochemical studies on S. hypericifolia. Nevertheless, this species is of interest in terms of the research on the set and levels of phenolic compounds (PCs). N.D. Storozhenko [2] has found that the main $\mathrm{PCs}$ in the organs of the aerial and underground parts of $S$. hypericifolia are flavonoids and 
phenolcarboxylic acids. The following flavonoids have been found in the organs of $S$. hypericifolia: flavans ((+)-catechin, (-)-epicatechin, (+)-catechin-7-O- $\alpha$-Lrhamnopyranoside, and (+)-catechin-7- $\beta$-D-xylopyranoside) [3-4], flavones (apigenin, luteolin, apigenin-5- $\beta$-D-glucopyranoside, and luteolin-5- $\beta$-D-glucopyranoside) [5], and flavonols (quercetin, hyperoside, isoquercitrin, rutin, and avicularin) [2]. The following phenol carboxylic acids have been identified in the organs of $S$. hypericifolia: $p$-coumaric, trans-p-coumaric, cis-p-coumaric, p-oxybenzoic, caffeic, trans-caffeic, ferulic, trans-ferulic, and chlorogenic [2, 6]. Roots, bark, and leaves of $S$. hypericifolia are used in the treatment of gastrointestinal diseases, rheumatoid arthritis, helminthiases, and gynecological diseases in Tibetan medicine and for the treatment of dermatoses in traditional Kazakh medicine. Infusion of flowers is used against algomenorrhea [7]. Flavans of S. hypericifolia have low toxicity and good anticancer effects both on their own and in combination with radiation therapy according to in vivo and in vitro experiments. A fungicidal activity of the phenolic acids isolated from $S$. hypericifolia leaves has been documented [2]. An aqueous-ethanol extract from this plant shows the highest antiviral activity among representatives of the Spiraea genus of Asian Russia [8]. The search for plants and their formulations with high concentration of pharmacologically active substances is important for the development of the pharmaceutical industry and of the phytoresource base of our region as well as for rational use of biological resources of Siberia.

The aims of the present study were a comparative analysis of morphological characteristics as well as qualitative and quantitative assays of PCs in the leaves of $S$. hypericifolia growing under natural conditions in Novosibirsk Oblast.

\section{Materials and methods}

S. hypericifolia at the flowering stage was sampled randomly in 2019 at four natural sites in Novosibirsk Oblast: No. 1: Iskitimsky district, near village Novososedovo, Ecological Park "Berd Rocks"; No. 2 and No. 3: Toguchinsky district, near the village of Gorny, Lysaya hill; and No. 4: Kupinsky district, near the Steklyannoye village. Different morphological varieties of $S$. hypericifolia were found in the population growing near the village of Gorny on Lysaya Hill. Typical S. hypericifolia plants with an average height of up to $50 \mathrm{~cm}$ prevailed in this population (site No. 2), and there was a separate group there of individuals $>100 \mathrm{~cm}$ high and with a larger leaf blade (site No. 3).

In the analysis of the morphological variation of Spiraea, we used the technique developed by S.A. Mamaev [9]. To assess individual differences in plant height and leaf blade parameters (length and width), 30 individuals in a middle-aged generative state were examined in each population. The leaf blade was collected from the middle part of the branch.

PCs were analyzed in the leaves of S. hypericifolia. The leaves were dried separately in the open air in a shadow. Afterwards, the dry material was shredded to $2-3 \mathrm{~mm}$ pieces and blended, and representative leaf samples were chosen. PCs were studied in $40 \%$ aqueousethanol extracts obtained via extraction on a water bath.

This analysis was carried out on an Agilent 1200 HPLC system including a Zorbax SBC18 column $(5 \mu \mathrm{m}, 4.6 \times 150 \mathrm{~mm})$ and equipped with a diode array detector and a ChemStation system for the collection and processing of chromatographic data (Agilent Technology, Palo Alto, CA, USA), by the method of T.A. van Beek [10] with modifications. The separation was conducted under the following conditions: for $27 \mathrm{~min}$, a gradient from $31 \%$ to $33 \%$ of methanol acidified in phosphoric acid $(0.1 \%)$; next, in the mobile phase, the concentration of methanol in the solution of phosphoric acid $(0.1 \%)$ was changed from $33 \%$ to $46 \%$ for $11 \mathrm{~min}$, then from $46 \%$ to $56 \%$ during the next $12 \mathrm{~min}$, and from $56 \%$ to $100 \%$ during 4 min (solvent system I). The eluent flow rate was $1 \mathrm{ml} / \mathrm{min}$, 
column temperature was $26^{\circ} \mathrm{C}$, and sample volume $10 \mu \mathrm{l}$, and detection was conducted at wavelengths of 254, 270, 290, 340,360, and $370 \mathrm{~nm}$. Quantification of individual PCs in the plant samples was performed by an external standard method [10]. Levels of individual PCs were calculated by means of hyperoside. The samples were analyzed thrice.

The analysis of free aglycones that formed after acid hydrolysis of the corresponding flavonoid glycosides was carried out due to the lack of available standard samples and difficult separation conditions [10]. To this end, $0.5 \mathrm{ml}$ of $\mathrm{HCl}(2 \mathrm{~N})$ was added to $0.5 \mathrm{ml}$ of a leaf extract. The mixture was heated on a boiling water bath for $2 \mathrm{~h}$. Chromatographic analysis was conducted in gradient elution mode in solvent system II: i.e., in the mobile phase, methanol concentration in the aqueous solution of phosphoric acid $(0.1 \%)$ was changed from $45 \%$ to $48 \%$ during 18 min. Detection was conducted at $370 \mathrm{~nm}$. Concentrations of flavonoid glycosides (glycosides of quercetin, kaempferol, and isorhamnetin separately) in the plant samples were calculated from the levels of free aglycones that formed after the acid hydrolysis. Coefficients retrieved from the literature were employed to convert the aglycone concentrations to the concentrations of respective glycosides: 2.504 for quercetin, 2.588 for kaempferol, and 2.437 for isorhamnetin [10].

\section{Results and discussion}

The comparative data on morphological parameters of S. hypericifolia from the four natural sites in Novosibirsk Oblast are summarized in Table 1. This analysis revealed two morphological varieties of $S$. hypericifolia. Plants from three sites: No. 1 (near the village of Novososedovo), No. 2 (near the village of Gorny), and No. 4 (near the village of Steklyannoye) are characterized by an average height of up to $50 \mathrm{~cm}$. The specimens from these sites have average length $(8.2-9.1 \mathrm{~mm})$ and width $(3.3-3.5 \mathrm{~mm})$ of the leaf blade and average area of the leaf blade $\left(22.0-25.2 \mathrm{~mm}^{2}\right)$. By contrast, the plants from site No. 3 (environs of village Gorny) are twofold higher $(104 \mathrm{~cm})$ compared to the other studied plants. Similarly, the leaf blade length $(13.5 \mathrm{~mm})$, the leaf blade width $(5.5 \mathrm{~mm})$, and the leaf blade area $\left(56.2 \mathrm{~mm}^{2}\right)$ in plants from this site are $1.5-2.0$-fold greater than those at the other sites.

Table 1. Comparison of S. hypericifolia morphological features

\begin{tabular}{|l|c|c|c|c|}
\hline \multicolumn{1}{|c|}{ Site ID } & $\begin{array}{c}\text { Plant height, } \\
\mathrm{cm}\end{array}$ & $\begin{array}{c}\text { Leaf area, } \\
\mathrm{mm}^{2}\end{array}$ & $\begin{array}{c}\text { Leaf blade } \\
\text { length, } \mathrm{mm}\end{array}$ & $\begin{array}{c}\text { Leaf blade } \\
\text { width, } \mathrm{mm}\end{array}$ \\
\hline 1. Novososedovo & $40.64 \pm 1.59$ & $24.86 \pm 1.15$ & $9.1 \pm 0.15$ & $3.35 \pm 0.06$ \\
\hline 2. Gorny, average plants & $40.26 \pm 1.79$ & $21.97 \pm 1.03$ & $8.21 \pm 0.13$ & $3.27 \pm 0.07$ \\
\hline 3. Gorny, tall plants & $104.2 \pm 3.71$ & $56.17 \pm 5.02$ & $13.54 \pm 0.43$ & $5.53 \pm 0.19$ \\
\hline 4. Steklyannoye & $40.45 \pm 1.64$ & $25.17 \pm 0.88$ & $8.9 \pm 0.11$ & $3.46 \pm 0.06$ \\
\hline
\end{tabular}

Note: The data are presented as mean \pm standard deviation $(n=30)$.

In the PC profiling in solvent system I, it was demonstrated that no fewer than 23 PCs are present in the aqueous-ethanol extracts from $S$. hypericifolia leaves (Table 2). Three acids (chlorogenic, $p$-hydroxybenzoic, and $p$-coumaric) and six flavonols were identified: quercetin and its glycosides (hyperoside, isoquercitrin, avicularin, and rutin) and a kaempferol glycoside (astragalin). The PCs were identified by means of UV spectra and a comparison of retention times in the chromatograms with those of standard samples.

The comparative analysis of chromatograms showed that the PC sets of $S$. hypericifolia leaves are similar among the four sites. Hyperoside (6.7-20.5 mg/g), isoquercitrin $(0.6-4.2 \mathrm{mg} / \mathrm{g})$, rutin $(0.6-2.1 \mathrm{mg} / \mathrm{g})$, avicularin $(2.3-7.0 \mathrm{mg} / \mathrm{g})$, quercetin $(0.9-1.7 \mathrm{mg} / \mathrm{g})$, and chlorogenic acid $(0.5-2.3 \mathrm{mg} / \mathrm{g})$ turned out to be the main PCs in the extracts from $S$. hypericifolia leaves. 
The highest total level of identified PCs was found at site No. 4, collected near the village of Steklyannoye $(39.1 \mathrm{mg} / \mathrm{g}$; Table 2). Plants from this site are distinguished by the levels of the following major PCs: hyperoside $(20.5 \mathrm{mg} / \mathrm{g})$, avicularin $(7.0 \mathrm{mg} / \mathrm{g})$, isoquercitrin $(4.2 \mathrm{mg} / \mathrm{g})$, and chlorogenic acid $(2.3 \mathrm{mg} / \mathrm{g})$; this result is most likely related to the growth conditions. It is known that the most stressful factors for natural growth of plants - an increase in altitude, increased UV radiation, and decreases in moisture and the sum of positive Celsius temperatures-affect the synthesis of flavonols in plant cells [11]. The concentration of PCs proved to be average in the leaves of plants from site No. 1 (the vicinity of village Novososedovo; $18.9 \mathrm{mg} / \mathrm{g}$ ) and site No. 2 (the vicinity of village Gorny; $25.9 \mathrm{mg} / \mathrm{g}$ ). The lowest concentration of PCs was found in plants from site No. 3 (collected in the vicinity of village Gorny on the Lysaya hill; $13.5 \mathrm{mg} / \mathrm{g}$ ). The level of PCs in aqueousethanol extracts from the leaves of these plants is almost threefold lower as compared to site No. 4 (Table 2). Plants from site No. 3 differ from all others in morphological characteristics (Table 1).

To quantify flavonoid glycosides separately, acid hydrolysis of the aqueous-ethanol extracts from the leaves and inflorescences was carried out next. In the chromatographic analysis of $S$. hypericifolia leaves in solvent system II, three flavonol aglycones were detected: quercetin, kaempferol, and isorhamnetin (Table 1). Quercetin was the dominant $\mathrm{PC}$ in the leaves. During the conversion of aglycone concentrations to the corresponding glycoside concentrations, it was demonstrated that the highest total level of quercetin glycosides is present in the leaves from site No. 4 (in the vicinity of village Steklyannoye; $34.5 \mathrm{mg} / \mathrm{g}$ ). Plants from this site are also characterized by the highest concentration of kaempferol glycosides $(3.2 \mathrm{mg} / \mathrm{g})$ and isorhamnetin glycosides $(1.8 \mathrm{mg} / \mathrm{g})$. Levels of quercetin and kaempferol glycosides proved to be average at sites No. 1 and 2 . The lowest concentration of these substances was seen in the plants with large leaf blades (site No. 3).

The plant specimens from site No. 3 have large leaf blades and the lowest level of PCs in the leaves. Plants from sites No. 1, 2, and 4 were found to have an average size of the leaf blade and average height; however, they are characterized by higher concentration of PCs. We showed that the concentration of PCs differs almost twofold between two analyzed specimens from the sites (No. 2 and 3) that have the same natural conditions with identical insolation (Lysaya hill, environs of the village of Gorny). The total level of the identified PCs was $25.9 \mathrm{mg} / \mathrm{g}$ in plants with average morphological parameters (site No. 2), whereas this parameter was $13.5 \mathrm{mg} / \mathrm{g}$ in the tall plants with large leaves (site No. 3). The increase in plant size was associated with a decrease in the concentration of PCs in $S$. hypericifolia leaves. Probably composition of the soils influenced both the plant size and the PC level in the plants' leaves in the vicinity of the Gorny village.

Table 2. Characteristics and levels of the PCs detected by high-performance liquid chromatography in the aqueous-ethanol extracts of $S$. hypericifolia leaves

\begin{tabular}{|c|c|c|c|c|c|c|}
\hline \multirow{3}{*}{$\begin{array}{c}\text { Peak } \\
\text { No. }\end{array}$} & \multirow{3}{*}{$\begin{array}{c}\text { Compound (spectral } \\
\left.\text { characteristics, } \lambda_{\max }, \mathrm{nm}\right)\end{array}$} & \multirow{3}{*}{$\begin{array}{l}\text { Retention } \\
\text { time, min }\end{array}$} & \multicolumn{4}{|c|}{ Level, $\mathrm{mg} / \mathrm{g}$ of air-dried material } \\
\hline & & & Site 1 & Site 2 & Site 3 & Site 4 \\
\hline & & & Novososedovo & $\begin{array}{c}\text { Gorny, } \\
\text { average } \\
\text { plants }\end{array}$ & $\begin{array}{l}\text { Gorny, } \\
\text { tall plants }\end{array}$ & Steklyannoye \\
\hline \multicolumn{7}{|c|}{ Extracts (solvent system I) } \\
\hline 1 & $\begin{array}{l}\text { chlorogenic acid } \\
(244,330)\end{array}$ & 3.2 & $0.5 \pm 0.09$ & $1.2 \pm 0.04$ & $0.7 \pm 0.002$ & $2.3 \pm 0.12$ \\
\hline 2 & $\begin{array}{l}p \text {-hydroxybenzoic acid } \\
(205,255)\end{array}$ & 4.3 & $0.23 \pm 0.05$ & $0.21 \pm 0.05$ & $0.15 \pm 0.05$ & $0.33 \pm 0.09$ \\
\hline 3 & $\begin{array}{l}p \text {-coumaric acid } \\
(226,310)\end{array}$ & 7.9 & $0.43 \pm 0.1$ & $0.75 \pm 0.12$ & $0.57 \pm 0.09$ & $0.78 \pm 0.12$ \\
\hline 4 & hyperoside & 18.0 & $10.08 \pm 0.12$ & $12.91 \pm 1.1$ & $6.66 \pm 0.58$ & $20.47 \pm 1.3$ \\
\hline
\end{tabular}




\begin{tabular}{|c|l|c|c|c|c|c|}
\hline 5 & isoquercitrin $(259,358)$ & 19.3 & $0.61 \pm 0.07$ & $2 \pm 0.27$ & $1.35 \pm 0.1$ & $4.19 \pm 0.09$ \\
\hline 6 & $\begin{array}{l}\text { rutin } \\
(256,358)\end{array}$ & 20.0 & $0.95 \pm 0.01$ & $2.07 \pm 0.07$ & $0.62 \pm 0.05$ & $2 \pm 0.05$ \\
\hline 7 & $\begin{array}{l}\text { avicularin } \\
(260,360)\end{array}$ & 28.4 & $4.46 \pm 0.08$ & $4.61 \pm 0.12$ & $2.33 \pm 0.04$ & $7.02 \pm 0.11$ \\
\hline 8 & $\begin{array}{l}\text { astragalin } \\
(265,350)\end{array}$ & 32.5 & $0.28 \pm 0.07$ & $0.42 \pm 0.04$ & $0.26 \pm 0.04$ & $0.64 \pm 0.06$ \\
\hline 9 & $\begin{array}{l}\text { quercetin } \\
(255,372)\end{array}$ & 40.6 & $1.37 \pm 0.006$ & $1.71 \pm 0.07$ & $0.86 \pm 0.04$ & $1.32 \pm 0.08$ \\
\hline \multicolumn{7}{|c|}{ Sum of identified substances } \\
\hline \multicolumn{7}{|c|}{ Hydrolysates of extracts (solvent system II) } \\
\hline 1 & quercetin glycosides* & 6.6 & $19.33 \pm 0.22$ & $24.02 \pm 0.2$ & $16.82 \pm 0.0$ & $34.48 \pm 0.5$ \\
\hline 2 & kaempferol glycosides* & 11.1 & $1.06 \pm 0.02$ & $1.95 \pm 0.02$ & $0.83 \pm 0.09$ & $3.17 \pm 0.00$ \\
\hline 3 & isorhamnetin glycosides* & 12.4 & $0.45 \pm 0.02$ & $1.24 \pm 0.02$ & $0.80 \pm 0.05$ & $1.79 \pm 0.04$ \\
\hline
\end{tabular}

Note. mean and standard deviation $(\mathrm{n}=3)$. *The concentrations of aglycones were converted to those of the corresponding glycoside via coefficients from the literature (subsection 2).

\section{Conclusion}

Two phenotypic varieties of $S$. hypericifolia growing in Novosibirsk Oblast were discovered in this comparative study of morphological characteristics of the plants at four natural sites; the sets and levels of PCs in S. hypericifolia leaves were compared too. The doubling of plant size is associated with a decrease in the leaf concentration of PCs.

The work was supported by a publicly funded project for the Central Siberian Botanical Garden (the Siberian Branch of the Russian Academy of Sciences), No. AAAA-A21121011290025-2.

Acknowledgements. The English language was corrected and certified by shevchukediting.com

\section{References}

1. A. V. Polozhij, Flora of Siberia, 8 (Nauka, Novosibirsk, 1988)

2. N. D. Storozhenko, Polyphenolic compounds of the Spiraea hypericifolia L. (Irk., 1977)

3. L. T. Pashinina, N. D. Storozhenko, T. K. Chumbalov, Chem. Nat. Compd., 12 (1976)

4. T. K. Chumbalov, L. T. Pashinina, N. D. Storozhenko, Chem. Nat. Compd., 12 (1976)

5. T. K. Chumbalov, L. T. Pashinina, N. D. Storozhenko, Chem. Nat. Compd., 11 (1975)

6. E. A. Karpova, O. V. Imetkhenova, Turczaninowia, 17 (2015)

7. Plant resources of the USSR: flowering plants, their chemical composition, use. Family Hydraginaceae - Haloragaceae (Nauka, L., 1987)

8. V. A. Kostikova, E. I. Filippova, G. I. Vysochina et al., Antiviral activity of plants of the genus Spiraea (Rosaceae) growing in the Asian part of Russia. Conf. dedicated to the 70th anniversary of Central Siberian Botanical Garden, 1-8 August 2016, Novosibirsk (2016)

9. S. A. Mamaev, Forms of intraspecific variability of woody plants (on the example of the family Pinaceae in the Urals) (Nauka, M., 1973)

10. T. A. van Beek, P. Montoro, J. Chromatogr. A, 1216 (2009)

11. M. N. Zaprometov, Phenolic compounds: distribution, metabolism and function in plants (Nauka, M., 1994) 